\title{
Are potential organ donors missed on general wards? A 6-month audit of hospital deaths
}

The DonateLife

Audit appears

to be a robust

tool for

identifying

realistic

potential organ

donors

Jonathan J Gatward MBChB, FRCA, FCICM

Michael J O'Leary

$M D, F R C A, F C I C M$

Myra Sgorbini

MN(Hon)

Paul R Phipps PhD, FRACP, FCICM

Royal Prince Alfred Hospital Sydney, NSW.

laoire@mac.com

doi: 10.5694/mjal4.00316 n the decade to 2008, the deceased donor and organ transplant rates in Australia failed to increase in line with population growth, and there was little change in the number of patients needing organ transplantation. ${ }^{1}$ In response to this, the Australian Government set out the National Reform Programme, comprising nine measures to establish the world's best practice in organ and tissue donation. $^{2}$

An important part of the national approach is the DonateLife Audit, which aims to report on all actual and potential organ donation activity: donor identification, request and consent rates; reasons why donation does not proceed; and missed donation opportunities. Data are collected on all deaths of patients aged between 28 days and 80 years in the emergency department (ED) and intensive care unit (ICU) (or on the wards if discharged from the ED or ICU in the previous 24 hours) and deaths of any other patient when organ donation is considered.

Royal Prince Alfred Hospital has been contributing to the DonateLife Audit since its inception, and we believe that we miss very few potential organ donors from EDs and ICUs. The DonateLife Audit does not, however, consider whether potential organ donors on the general wards who have not been recently discharged from the ICU or ED have been missed.

The success of organ donation programs is defined by the rate of deceased organ donors per million population (dpmp). Australia's rate increased from 9-12 dpmp in 2009 to over $16 \mathrm{dpmp}$ in $2013 .{ }^{3}$ Despite this, there is a body of opinion in Australia that progress has been too slow and not reflective of the large increase in funding that the reform committed. ${ }^{4}$ Furthermore, the change has not been uniform, with New South Wales achieving only $14.2 \mathrm{dpmp}$ in 2013.

\section{Abstract}

Objective: To determine whether potential organ donors are being missed on general wards by the DonateLife Audit, which concentrates on patients dying in emergency departments and intensive care units.

Design, setting and patients: Six-month (1 July to 31 December 2012) retrospective audit of patient deaths in a 700-bed metropolitan Australian tertiary referral and teaching hospital.

Main outcome measure: Potential organ donor suitability as assessed by a panel of organ donation specialists.

Results: In total, 427 patients died, including nine neonates (2.1\%) who were not further assessed and 175 patients (41.0\%) who were excluded on the basis of age contraindicating organ donation ( $\geqslant 80$ years). Seventyeight $(18.3 \%)$ were excluded on the basis of active cancer or palliative care for cancer and 143 (33.5\%) were deemed otherwise not medically suitable. Twelve $(2.8 \%)$ had been referred to the DonateLife team for consideration for organ donation. Ten (2.3\%) were submitted for panel review, and of these only three were considered to have "potential to develop brain death within 24 hours". These patients would have required mechanical ventilation if potential organ donation were to be realised. One additional potential candidate for donation after circulatory death was identified in the intensive care unit.

Conclusion: We identified very few potential organ donors among patients who died outside the emergency department and intensive care unit. For these patients to have progressed to organ donation, medical interventions not in keeping with standard Australian practice would have been required. The DonateLife Audit appears to be a robust tool for identifying realistic potential organ donors.

The increased donation rate falls well short of the rates reported for the highest performing countries, such as Spain (over $35 \mathrm{dpmp}$ ). ${ }^{5}$ It has been suggested that not all potential donors are being identified in Australian hospitals and that changes in hospital practice are needed to further increase donation rates. ${ }^{4,6}$

We conducted an audit of hospital deaths to examine whether potential organ donors outside the DonateLife Audit areas of EDs and ICUs are being missed. The potential for tissue-only donation was not investigated.

\section{Methods}

The audit was conducted at Royal Prince Alfred Hospital, a metropolitan 700-bed tertiary referral and teaching hospital in NSW. Specialties include neurology and neurosurgery, patients include rural and out-of-catchment referrals and patients admitted through the ED, and there is a 50-bed intensive care floor. Hospital deaths between 1 July and 31 December 2012 were reviewed by two donation specialists medical (DSMs) (both intensive care specialists) and a donation specialist nurse (DSN).

The following groups of patients were excluded from further review as they are generally deemed unsuitable for organ donation: those who died when they were aged $\geqslant 80$ years; those admitted to hospital under oncology, palliative care for cancer or haematology services (ie, those with an oncological diagnosis); and those who could not be resuscitated from cardiac arrest in the ED. Neonates who died when they were aged $\leqslant 28$ days were excluded, in keeping with the DonateLife Audit.

Patients referred to the DonateLife team were categorised according to standard potential organ donor categories by the DSN (Box 1). ${ }^{7}$ The remaining patients were then assessed independently for suitability 


\section{Potential organ donor categories}

Category A: Confirmed brain death (BD)

Category B: Probable BD (BD was not formally diagnosed but, based on chart review, the patient was likely to have fulfilled the criteria for BD)

Category C: Imminent BD (potential to develop BD within 24 hours of endof-life decision making if supportive treatment had been continued)

Category D: Low or no potential to progress to BD

Potential donation after circulatory death: Medically suitable for organ donation and thought to be likely to progress to circulatory death within 90 minutes of withdrawal of cardiorespiratory support

and likelihood of progression to organ donation by the two DSMs, using the hospital's electronic medical records. Where there was disagreement, the DSN reviewed the case record and had the casting vote.

Patients were deemed not medically suitable (NMS) if they were aged $>65$ years and had a non-neurological diagnosis, as such patients would have been highly unlikely to become brain dead and were over the age accepted in NSW in 2012 for donation after circulatory death (DCD). Patients who had active cancer, had septicaemia or were dying a circulatory death despite maximal medical therapy were also deemed NMS, as these conditions contraindicate organ donation. Patients who died with multiple organ failure (defined as presence of two or more organ failures) were analysed individually to establish whether non-failed organs might have been suitable for donation. Finally, patients were deemed NMS if a treatment limitation stating that they were not to receive mechanical ventilation had been made.

The remaining patient deaths, where we could not establish a clear reason to exclude the potential for organ donation, were reviewed in detail and assigned to potential organ donor categories by a panel of five organ donation specialists. The panel consisted of three DSMs, the DSN from Royal Prince Alfred Hospital and, to ensure that the study embraced

\begin{tabular}{|c|c|c|c|c|}
\hline Age & $\begin{array}{l}\text { Intensive care } \\
\text { unit }(n=102)\end{array}$ & $\begin{array}{c}\text { Ward } \\
(n=283)\end{array}$ & $\begin{array}{c}\text { Emergency } \\
\text { department } \\
(n=33)\end{array}$ & $\begin{array}{c}\text { Neonatal intensive } \\
\text { care unit and } \\
\text { delivery suite } \\
(n=9)\end{array}$ \\
\hline$\leqslant 65$ years & 49 (48.0\%) & $57(20.1 \%)$ & $7(21.2 \%)$ & $9(100.0 \%)$ \\
\hline $66-79$ years & $30(29.4 \%)$ & 92 (32.5\%) & $8(24.2 \%)$ & 0 \\
\hline$\geqslant 80$ years & $23(22.5 \%)$ & $134(47.3 \%)$ & $18(54.5 \%)$ & 0 \\
\hline
\end{tabular}

the same medical standards of donor evaluation as the highest performing country, a medical donation specialist from Spain.

The Sydney Local Health District Ethics Review Committee confirmed that ethics approval was not required for publication of the audit data.

\section{Results}

During the study period, there were 427 patient deaths. Their distributions by age and location are shown in Box 2. Most deaths of patients aged $\leqslant 65$ years who did not have cancer occurred in the ICU (39/48). Of patients aged $<80$ years who died on general wards, only 17 had neurological diagnoses.

\section{Excluded deaths}

Exclusions and disposition categories are shown in Box 3. On initial review, 262 patients were excluded; more than half of them were excluded on age grounds and 78 because of a diagnosis of active cancer.

Twenty-eight patients were excluded on the basis of multiple organ failure, of whom 24 died in the ICU and were thus already assessed by the DonateLife Audit tool (which identified none as a potential organ donor). The four multiple organ failure patients who died on general wards included three with end-stage liver failure and other organ failures, and one with an inoperable intracerebral haemorrhage and multiple organ dysfunction. In no case of multiple organ failure was it considered that donation of a non-failed organ might have been possible.

Nine patients had a treatment limitation in place precluding mechanical ventilation. Three of them had neurological diagnoses but were aged $>70$ years and thus unsuitable for consideration for DCD; these patients had low or no potential to progress to brain death (Category D, Box 1) and they all died on general wards late after hospital admission. Three patients died on general wards with end-stage respiratory disease for which mechanical ventilation was deemed inappropriate. One patient had a terminal illness with an advance care directive precluding mechanical ventilation, and one had end-stage liver failure and had been deemed too unwell to undergo liver transplantation. The other patient died in the ICU while receiving palliative care for a hypoxic brain injury many days after removal of mechanical ventilation.

\section{Organ donation referrals}

Twelve patients had been referred to the DonateLife team to be considered for organ donation, of whom three subsequently became organ donors $(<1 \%$ of patients who died in hospital). Of the other nine, DCD was planned for two patients, but this failed in both cases (death occurred greater than 90 minutes after withdrawal of mechanical ventilation); one was deemed NMS after the referral was made (and therefore consent was not sought); and six patients did not proceed to donation because consent was refused (in one case this was patient refusal on the NSW Roads and Traffic Authority [RTA] database).

\section{Deaths reviewed by expert panel}

Ten patients were reviewed in detail by the panel of organ donation specialists. Eight of them died on general wards. They were all aged $>65$ years, above the 2012 cut-off age for consideration of DCD in NSW, and 
would therefore have had to progress to brain death to be considered realistic potential organ donors. All eight had neurological diagnoses; five were deemed Category D and three were deemed Category C (Box 1). The three deemed Category $C$ might have become organ donors if they had received or had continued mechanical ventilation solely for the purpose of facilitating organ donation. The other two patients died in the ICU and were both aged $<65$ years. One had end-stage pulmonary fibrosis and was considered by the panel to be a potential DCD donor (considered but rejected for lung transplantation, consent for organ donation not sought), and the other had respiratory failure and was deemed to have failed supportive treatment.

\section{Comparison with DonateLife Audit}

During the study period, 16 patient deaths were entered into the DonateLife Audit. When compared with our audit, these included all 12 patients referred to the DonateLife team, three from the group that underwent panel review and one from the group of excluded deaths. The audit did not identify any missed potential organ donors who died in the ED or ICU.

\section{Discussion}

To our knowledge, this is the first comprehensive audit of all deaths in an Australian hospital to evaluate potential for organ donation, including both donation after brain death (DBD) and DCD. Over 6 months at Royal Prince Alfred Hospital, we identified three patients who died outside the ED or ICU for whom there was a possibility of progression to brain death within 24 hours and the potential to become organ donors. Meanwhile, the DonateLife Audit did not identify any missed potential organ donors who died in the ED or ICU. Furthermore, for the three potential organ donors to have progressed to organ donation, medical interventions that are not in keeping with standard Australian practice would have been required.

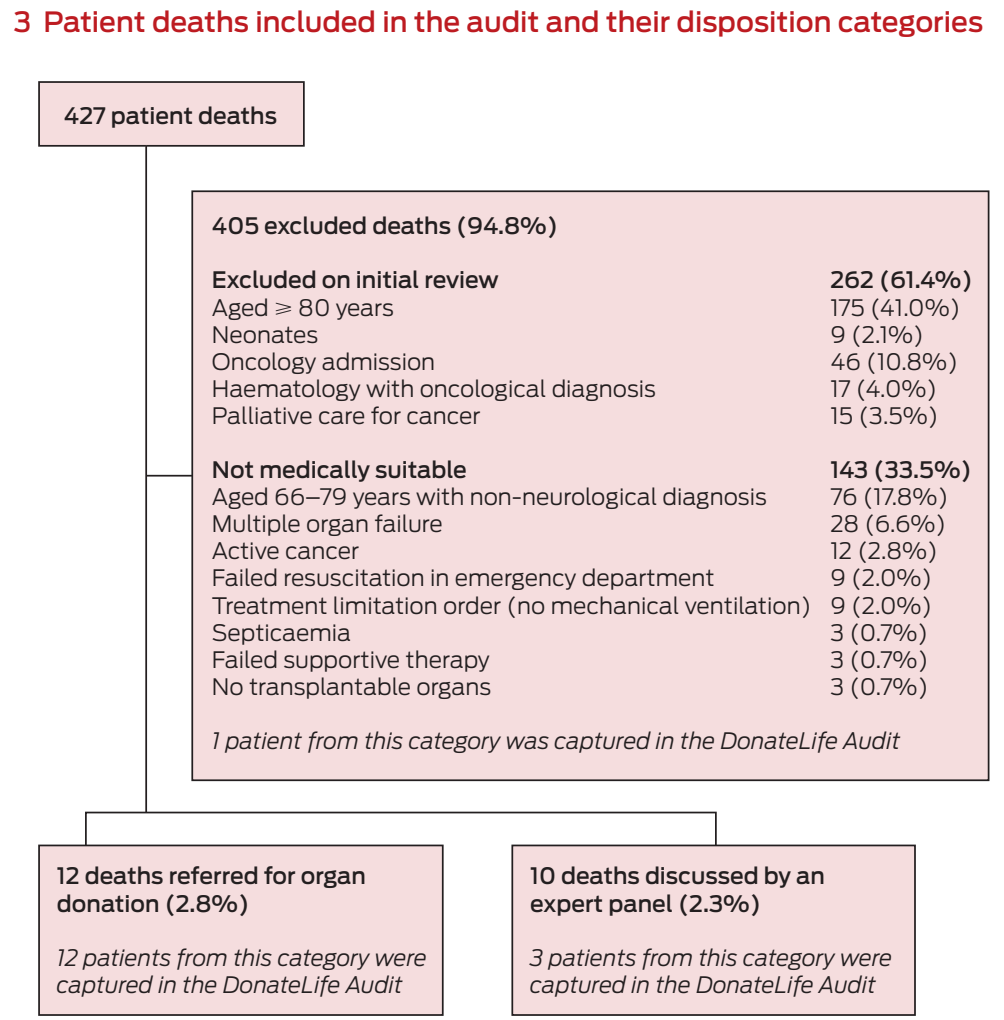

\footnotetext{
4 Maastricht classification for donation after circulatory death ${ }^{9}$

Category 1: Dead on arrival to hospital

Category 2: Failed resuscitation in the emergency department or intensive care unit

Category 3: Withdrawal of treatment in the intensive care unit

Category 4: Cardiac arrest following determination of brain death but before planned organ procurement
}

The principal potential weakness of our study was its pragmatic nature. This meant that we might have excluded some potential organ donors.

The most common reason for which patients were excluded was age. Some of those we excluded on this basis might represent missed potential organ donors because the age cutoffs for organ donation have been increasing over the years, with those aged over 80 years increasingly considered for DBD and those aged over 65 years for DCD. ${ }^{8}$ In accordance with the DonateLife Audit, neonates under 28 days old were excluded, but it is possible for neonates to be considered for organ donation.

The second most common reason for exclusion was an oncological diagnosis. We excluded patients on the basis of a listed diagnosis of malignancy without further review. As some patients with low-grade, confined malignancies can be considered for organ donation, ${ }^{8}$ a small number of patients excluded due to malignancy might have been potential donors.

We excluded three patients due to septicaemia, and we excluded other patients who had septicaemia on the basis of multiple organ failure. However, organ donation can occasionally be considered in patients diagnosed with septicaemia that is deemed treatable in either the donor or the recipient and in patients who have received 24-48 hours of treatment for suspected septicaemia. ${ }^{8}$

We did not consider patients who died after failed cardiopulmonary resuscitation in the ED as potential 
organ donors. DCD is classified using the Maastricht classification (Box 4). ${ }^{9}$ In Australia, only patients in Categories 3 and 4 are regarded by the Australian and New Zealand Intensive Care Society as suitable for DCD. ${ }^{10}$ This is in contrast to the situation in some other countries where "uncontrolled" DCD (Category 2) is practised. In the Madrid region of Spain, for example, uncontrolled DCD accounted for $41 \%$ of deceased organ donors in 2012. ${ }^{11}$

Our audit confirmed that only a small number of patients who die in hospital are potentially suitable for organ donation. Of the 12 referred to the DonateLife team, only three progressed to organ donation, with refusal of consent (50\%) being the principal reason that organ donation did not proceed.

Only three of the 10 additional patients whose cases underwent panel review were assessed as Category $\mathrm{C}$ potential organ donors. Two of them would have required initiation of mechanical ventilation in the ED solely for the purposes of organ donation, and one might have undergone a longer period of mechanical ventilation in the ICU to allow for possible progression to brain death. There was only one potential DCD organ donor (who was rejected for lung transplantation) who might have been referred to the DonateLife team.

It is not current Australian practice to perform tracheal intubation and mechanical ventilation solely for the purposes of facilitating organ donation. Patients who require this solely for organ donation therefore represent potential organ donors, but only if there was a change to medical practice. This would require a complex and open debate in the medical and general community.

The finding that most deaths of patients aged $\leqslant 65$ years who did not have cancer occurred in the ICU confirms that it is unlikely that there is a large pool of potential DCD organ donors dying on the general wards. Furthermore, the small number of patients aged $<80$ years who died on general wards with a primary neurological diagnosis suggests that there is also not a substantial pool of potential DBD organ donors dying outside the ED and ICU.

Although the deceased organ donor rate is increasing in Australia, it is substantially lower than the highest performing countries (eg, Spain ${ }^{5}$ ). For this reason, we believe that more should be done to identify potential organ donors. While the use of uncontrolled DCD organ donors is common in some Spanish hospitals, this makes up only about $4 \%$ of total Spanish deceased organ donors. ${ }^{5}$

Of more importance is the incidence of brain death, which in Spain is more than double that in Australia. ${ }^{12}$ It has been suggested that the higher rate of brain death, and thus organ donors, might at least partly be explained by a practice of actively seeking potential organ donors outside the ICU and possibly a low tendency in Spanish ICUs to transition away from active treatments and towards palliative care when survival seems unlikely.

We conducted this audit to identify whether there were patients dying in our general wards who might have had the potential to become organ donors if treated differently. We identified only three such patients. It is likely that the major changes in Australian medical practice that would be required to recruit these potential organ donors would result in only a small change in organ donor numbers at best, but at the expense of a potentially less benevolent approach to palliation at the end of life.

A significant and important difference between Australian and Spanish practices highlighted by this audit is the low rate of next-of-kin consent for organ donation in Australia compared with Spain (61\% v 84\% during the period 2012-2013). ${ }^{3,5}$ An increase in next-of-kin consent rate (for the patients referred to the DonateLife team for whom consent was sought [ie, 12 minus the one deemed NMS and one with refusal on the RTA database]) from the $50 \%$ seen in our audit to $84 \%$ would have increased our consented organ donor number from five to eight without the need to seek any additional potential or marginal organ donors across the hospital.

We believe our data show that the DonateLife Audit is a robust tool for monitoring identification of potential organ donors in Australia and that extending its scope beyond the ICU and ED would not achieve a substantial increase in identification of potential donors. It appears that the principal factors affecting the lower organ donation rate in Australia compared with countries such as Spain are the lower rates of brain death and consent. Maximising consent rates is likely to be the single most effective intervention to increase organ donor numbers within existing medical practice in Australia.

Acknowledgements: We thank Xavier Guasch (Donation and Transplantation Institute, Barcelona, Spain) for helping with our case review.

Competing interests: No relevant disclosures.

Received 6 Mar 2014, accepted 23 Sep 2014. 
1 National Clinical Taskforce on Organ and Tissue Donation. National Clinical Taskforce on Organ and Tissue Donation final report: think nationally, act locally. Canberra: Department of Health and Ageing, 2008.

2 Australian Government Organ and Tissue Authority. National Reform Programme. http://www.donatelife. gov.au/about-us/national-reformprogramme (accessed Sep 2014).

3 Australian Government Organ and Tissue Authority. Performance report 2013. Canberra: OTA, 2014. http://www. donatelife.gov.au/sites/default/files/ files/OTA_2013_Performance_Report. pdf (accessed Sep 2014).

4 Hansen J. Gift of life campaign: patients are missing out on life saving transplants. The Sunday Telegraph (Sydney) 2013; 2 Nov. http://www.dailytelegraph. com.au/news/nsw/gift-of-lifecampaign-patients-are-missingout-on-life-saving-transplants/ story-fniOcxl2-1226751809803 (accessed Nov 2013).
5 Organización Nacional de Trasplantes. [Report of the quality assurance program (1998-2012)] [Spanish]. Madrid: ONT, 2013. http://www.ont. es/infesp/DocumentosCalidad/ Memoria\%20PGC_2012.pdf (access Feb 2015).

6 Outcomes Australia. ShareLife: an Outcomes Australia project. Why are we doing it? Organ donation in Australia. http://www.sharelife.org.au/ why.html (accessed Mar 2014).

7 Opdam HI, Silvester W. Potential for organ donation in Victoria: an audit of hospital deaths. Med J Aust 2006; 185: 250-254.

8 Australasian Transplant Coordinators Association. National guidelines for organ and tissue donation. 4th ed. ATCA, 2008. http://www.atca.org.au/ files/F.pdf (accessed Sep 2014).

9 Kootstra G, Daemen JH, Oomen AP. Categories of non-heart-beating donors. Transplant Proc 1995; 27: 2893-2894.
10 Australian and New Zealand Intensive Care Society. The ANZICS statement on death and organ donation. Edition 3.2. Melbourne: ANZICS, 2013.

11 Servicio Madrileno de Salud, Oficina Regional de Coordinación de Trasplantes. Report of transplants 2012 [Spanish]. Madrid: Communidad de Madrid, 2013.

12 Bendorf A, Kerridge IH, Stewart C. Intimacy or utility? Organ donation and the choice between palliation and ventilation. Crit Care 2013; 17: 316. 